\title{
CAPÍTULO 04: DESENVOLVIMENTO E AVALIAÇÃO QUALITATIVA DE SORVETE SIMBIÓTICO COM SORO DO LEITE E EXTRATO DE SOJA
}

\author{
CHAPTER 04: DEVELOPMENT AND QUALITATIVE EVALUATION OF \\ SYMBOTIC ICE CREAM WITH MILK SERUM AND SOY EXTRACT
}

\author{
Layane Rosa da Silva ${ }^{1}$; Antonio Alef Pereira de Oliveira ${ }^{2}$; Aliou Toro Lafia ${ }^{3}$; José Douglas \\ Bernardino Domingos ${ }^{4}$; Fabiana Augusta Santiago Beltrão ${ }^{5}$
}

\begin{abstract}
Resumo
O consumidor entende que alimentação saudável envolve a escolha de alimentos que, ao mesmo tempo, são capazes de fornecer os nutrientes necessários ao organismo e minimizar o risco de doenças. Portanto o objetivo desse estudo foi desenvolver um sorvete simbiótico com soro do leite e extrato de soja, e realizar a caracterização físico-química. Assim, com o objetivo de atender as expectativas dos consumidores em consumir um alimento funcional e nutritivo. $\mathrm{O}$ sorvete desenvolvido e analisado foi adicionado uma concentração de $10 \%$ de soro do leite e $10 \%, 15 \%$ e $20 \%$ de extrato de soja. As análises físico-químicas realizadas seguiram a metodologia proposta pelo Instituto Adolfo Lutz, a saber: determinação de sólidos solúveis totais, lactose, determinação da acidez com resultados expressos em g de ácido lático por cento, e determinação de gordura por Soxhlet. Os resultados mostraram valores diferentes para os diferentes tratamentos com exceção do teor de sólidos solúveis ( ${ }^{\circ}$ Brix), que correspondem a $1,20 \mathrm{em}$ todos os tratamentos. Com relação aos resultados de gordura a formulação 3, corresponde ao maior percentual com 52,33\%. Os alimentos adicionados de microrganismos probióticos estão sendo cada vez mais consumidos, principalmente devido aos efeitos benéficos atribuídos a esses microrganismos. Pesquisas já feitas, informam que a administração de ingredientes probióticos e prebióticos na alimentação resultam em efeitos benéficos à saúde do consumidor. O sorvete, é uma opção promissora para o desenvolvimento do produto funcional proposto. Os resultados deste trabalho podem contribuir para o desenvolvimento de novos produtos para a indústria alimentícia.
\end{abstract}

Palavras-Chaves: Sorvete, Simbiótico, Funcional, Probiótico, Prebiótico.

\begin{abstract}
The consumer understands that healthy eating involves choosing foods that, at the same time, are capable of providing the necessary nutrients to the body and minimizing the risk of diseases. Therefore, the objective of this study was to develop a symbiotic ice cream with whey and soy extract, and perform the physical-chemical characterization. Thus, in order to meet the expectations of consumers in consuming a functional and nutritious food. The developed and analyzed ice cream was added with a concentration of $10 \%$ whey and $10 \%, 15 \%$ and $20 \%$ soy extract. The physical-chemical analyzes carried out followed the methodology proposed by the Adolfo Lutz Institute, namely: determination of total soluble solids, lactose, determination of acidity with results expressed in $\mathrm{g}$ of lactic acid percent, and determination of fat by Soxhlet. The results showed different values for the different treatments with the exception of the content of soluble solids ( ${ }^{\circ}$ Brix), which correspond to 1.20 in all treatments. Regarding the fat results, formulation 3 , corresponds to the highest percentage with 52, 33\%. Foods added with probiotic

\footnotetext{
${ }^{1}$ Bacharelado em Agroindústria, Universidade Federal da Paraíba/UFPB, layanerossa@ gmail.com

${ }^{2}$ Bacharelado em Agroindústria, Universidade Federal da Paraíba/UFPB, aleffjoe@ gmail.com

${ }^{3}$ Mestrando em Tecnologia Agroalimentar, Universidade Federal da Paraíba/UFPB, zime1990@ gmail.com

${ }^{4}$ Bacharelado Nutrição e Dietética, Universidade Federal de Campina Grande/UFCG, douglas94nc@gmail.com

${ }^{5}$ Doutora em Biotecnologia, Universidade Federal da Paraíba/UFPB, fabs.15@ hotmail.com
} 
microorganisms are being increasingly consumed, mainly due to the beneficial effects attributed to these microorganisms. Research already done, inform that the administration of probiotic and prebiotic ingredients in the food results in beneficial effects to the consumer's health. Ice cream is a promising option for the development of the proposed functional product. The results of this work can contribute to the development of new products for the food industry.

Keywords: Ice cream, Symbiotic, Functional, Probiotic, Prebiotic.

\section{Introdução}

Os alimentos que estão sendo adicionados de microrganismos probióticos cada vez mais vem sendo amplamente consumidos, principalmente devido aos efeitos benéficos atribuídos a esses microrganismos, como: atividade antimicrobiana, estimulação do sistema imune, regulação intestinal, melhoria da digestão da lactose e atividade anticarcinogênica e antimutagênica. No entanto, é importante ressaltar que esses efeitos dependem do tipo de cepa probiótica administrada (BAŞYIĞIT; KULEAŞAN; KARAHAN, 2006; CRUZ et al., 2009).

Probióticos são definidos atualmente como micro-organismos vivos que, quando administrados em quantidades adequadas, conferem um benefício à saúde do hospedeiro (HILL et al., 2014). Os principais probióticos estudados e utilizados são as bactérias que pertencem aos gêneros Lactobacillus e Bifidobacterium (O'FLAHERTY; KLAENHAMMER, 2010; ROSS et al., 2010; RAMASAMY et al., 2012; SHARMA; DEVI, 2014).

Os efeito benéficos dos probióticos são amplamente dependentes da sua capacidade de atingir o seu local de ação apropriado, geralmente o intestino distal, em estado viável e em populações suficientes (KENT; DOHERTY, 2014). Pesquisas envolvendo prebióticos estão sendo direcionadas no sentido de identificar aspectos de saúde associados à sua utilização, o que inclui a redução da diarreia, a modulação da resposta imune e o incremento na biodisponibilidade mineral (RASTALL; GIBSON, 2015).

O consumidor entende que alimentação saudável envolve a escolha de alimentos que, ao mesmo tempo, são capazes de fornecer os nutrientes necessários ao organismo e minimizar o risco de doenças como hipertensão, diabetes, osteoporose, doenças cardiovasculares, entre outras. Durante os últimos 60 anos, alimentos com atributos de saúde tornaram-se cada vez mais importantes e os estudos indicam que os consumidores dão igual peso para atributos de saúde e sensoriais no momento da escolha dos produtos alimentícios (CODRON et al., 2005).

A demanda por alimentos que fornecem benefícios à saúde de forma a reduzir o risco do aparecimento de doenças e que supram as necessidades nutricionais do organismo é cada vez mais evidente. A incorporação de microrganismos probióticos e ingredientes prebióticos aos alimentos pode agregar valor aos produtos e oferecer os benefícios dos alimentos funcionais 
se incluídos diariamente na dieta. O sorvete é uma excelente fonte de energia e, apesar de conter açucares e gorduras, é geralmente considerado um alimento nutritivo, uma vez que contém leite e frutas em sua formulação (GOFF; HARTEL, 2013).

A Agência Nacional de Vigilância Sanitária (ANVISA) determina normas e procedimentos para registrar os alimentos funcionais no Brasil. Para lançar um produto no mercado com um registro de um alimento com alegação de propriedades funcionais de saúde, esta deve seguir a legislação do Ministério da Saúde e apresentar um relatório técnico- científico com muitas informações que comprovam os seus benefícios e a garantia de segurança para seu consumo.

Alimento funcional é aquele que além de atender à necessidade nutricional básica do consumidor, quando consumido, resulta em efeitos metabólicos e/ou fisiológicos benéficos à saúde (ROBERFROID, 2000). Para que este tipo de alimento exerça seus efeitos benéficos para a saúde, a ingestão deve ocorrer diariamente (PANDIYAN et al., 2012).

A crescente preocupação com a saúde e o interesse no bem estar físico são as principais razões para o aumento do consumo de alimentos que garantem benefícios à saúde. Nos últimos anos, o alimento não é visto apenas como um veículo de nutrientes essenciais para assegurar o crescimento e o bom desenvolvimento do organismo, mas como uma via para melhorar o bem estar e a saúde (HASLER; BROWN, 2009).

A indústria láctea é amplamente favorecida para o desenvolvimento de alimentos funcionais do tipo probióticos, prebióticos e simbióticos, uma vez que esses ingredientes se adaptam bem às bases lácteas e essas por sua vez, são largamente aceitas pelo mercado consumidor (ALVES et al., 2013; CRUZ et al., 2009).

O sorvete, alimento de alto valor nutricional, é uma opção promissora para o desenvolvimento de produto funcional, pois sabe-se que a incorporação de microrganismos probióticos e inulina nesta matriz não afeta a qualidade global do produto, e, além de ser amplamente consumido por várias faixas etárias, corresponde às expectativas da procura por produtos saudáveis e saborosos ao paladar (SOUZA et al., 2010).

Assim como os probióticos, a administração de ingredientes prebióticos na alimentação, como a inulina, pode resultar em efeitos benéficos à saúde, como mudanças positivas significativas na microbiota intestinal humana (BRUZZESE et al., 2006; RAMIREZ-FARIAS et al., 2009), uma vez que esses ingredientes não são hidrolisados e nem absorvidos no trato gastrintestinal superior humano. Assim, são capazes de estimular seletivamente a multiplicação de bactérias benéficas no cólon (MATTILA-SANDHOLM et al., 2002), têm potencial para reprimir patógenos e limitar a virulência dos mesmos por imunoestimulação, promovendo 
resistência à colonização por microrganismos patogênicos, melhorando assim, a imunidade de quem consome essas substâncias (HAULY; MOSCATTO, 2002; SAAD, 2006).

O leite e seus derivados têm sido testados como alimentos funcionais e tem despertado grande interesse por parte da indústria de laticínios, com destaque para o soro obtido como um subproduto da produção de queijo, que vem sendo apontado como alimento funcional com vários benefícios à saúde (TAVARES; MALCATA, 2016). Na indústria de laticínios, o soro, que é gerado após o processo de coagulação da caseína, é um subproduto descartado na maioria das vezes. Para reduzir os danos ambientais causados pelo descarte deste material, muitas indústrias têm desenvolvido produtos baseados na utilização do soro de leite (BALDISSERA et al., 2011).

Em virtude do desejo por alternativas vegetarianas e da intolerância a produtos lácteos, a demanda mundial por produtos não derivados do leite está crescendo (FARNWORTH et al., 2007; PRADO et al., 2008; RIVERA-ESPINOZA; GALLARDO-NAVARRO, 2010). Nesse contexto, a soja aparece como um substituto ideal para o consumo, com características nutricionais intrínsecas favoráveis à saúde do consumidor. Na composição da soja encontramse em majoritário nutrientes como proteínas, lipídios e carboidratos. A soja também é importante fonte de outros compostos, tais como fibras, oligossacarídeos (rafinose e estaquiose), vitaminas e minerais, como o cálcio (ROSSI et al., 2011).

Portanto o objetivo deste trabalho foi desenvolver um sorvete simbiótico com soro do leite e extrato de soja em diferentes proporções para assim verificar a influência desses ingredientes na viabilidade dos probióticos e em suas características físico-químicas. A proporção utilizada para produção foi de $10 \%$ de soro do leite e extrato de soja acrescentado na formulação do sorvete natural.

\section{Material e Métodos}

As análises físico-químicas foram realizadas no Laboratório de Análises Físicoquímicas de Alimentos do CCHSA UFPB Campus III. Para análise físico-química foram determinados soídos solúveis totais usando um refratômetro ABBE, gordura (SOXHLET), lactose (LANE-EYNON) e acidez (titulação) segundo Instituto Adolfo Lutz (IAL, 2008).

Para determinação do teor de sólidos solúveis totais - SST, foi utilizado um Becker de $100 \mathrm{~mL}$ e bastão de vidro e refratômetro de ABBE (Figura 1). O procedimento aconteceu da seguinte forma: foram pesados $5.0088 \mathrm{~g}$ da amostra, depois o refratômetro foi aferido com água destilada colocando algumas gotas no prisma e logo a seguir feita a leitura, zerando o refratômetro. Depois de secar o prisma com algodão e acrescentar um pouco da amostra foi 
feita a leitura novamente, realizando 4 repetições, até padronizar, por Instituto Adolfo Lutz (IAL, 2008).

Para determinação de gordura pelo método de Soxhlet - foi utilizado um extrator de Soxhlet de $125 \mathrm{~mL}$, balão de Soxhlet de $125 \mathrm{~mL}$, balão de Soxhlet, condensador de refluxo, bateria de aquecimento, estufa a $105^{\circ} \mathrm{C}$, balança analítica, dessecador, pinça metálica, cartucho de Soxhlet, éter de petróleo. O procedimento aconteceu da seguinte forma: balão de Soxhlet foi previamente aquecido em estufa a $105{ }^{\circ} \mathrm{C}$ por 1 (uma) hora, e esfriado em dessecador durante 30 minutos e então pesado em balança analítica. Foram pesadas aproximadamente $5 \mathrm{~g}$ da amostra em uma balança analítica diretamente no cartucho de Soxhlet. O cartucho foi colocado com a amostra no extrator de Soxhlet. Depois o balão de Soxhlet foi acoplado ao extrator e adicionados $80 \mathrm{~mL}$ (balões de $125 \mathrm{~mL}$ ) éter de petróleo, e logo a seguir, levado o conjunto para a bateria de aquecimento onde foi acoplado ao condensador de refluxo. A água de refrigeração e a bateria de aquecimento foram ligadas e procedida a extração dos lipídeos por aproximadamente 6 (seis) horas. Após as 6 (seis) horas, houve a recuperação do solvente hexano, e o balão de Soxhlet foi levado com os lipídeos para uma estufa a $105^{\circ} \mathrm{C}$ durante 2 (duas) horas. Passadas as 2 (duas) horas, o balão de Soxhlet foi retirado da estufa e colocado em um dessecador durante 30 minutos. Após os 30 minutos, o balão de Soxhlet foi retirado do dessecador e pesado em uma balança analítica, por Instituto Adolfo Lutz (IAL, 2008).

Figura 1. Refratômetro utilizado para realização da análise físico-química dos sorvetes

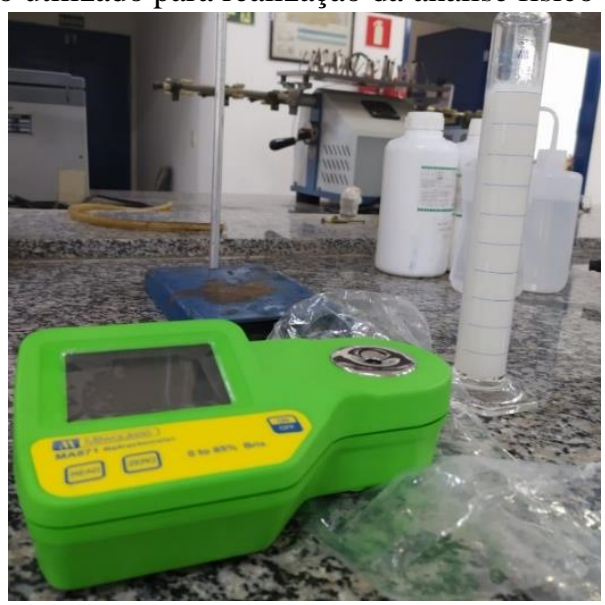

Fonte: Própria (2020).

Para determinação de glicídios redutores em lactose - aconteceu da seguinte forma: com auxílio de uma pipeta volumétrica foram transferidos $10 \mathrm{~mL}$ da amostra de sorvete simbiótico para balões volumétricos de $250 \mathrm{~mL}$, adicionados em cada balão $10 \mathrm{~mL}$ de água, 
$5 \mathrm{~mL}$ da solução de sulfato de zinco a $30 \%$ e $5 \mathrm{~mL}$ da solução de ferrocianeto de potássio a 15\%, após cada adição houve homogeneização. Depois ficou a sedimentar durante 5 minutos, o volume foi completado com água e o balão agitado para homogeneizar. Após homogeneização a amostra foi filtrada de forma límpida, em um frasco de Erlenmeyer de 300 $\mathrm{mL}$. Para um balão de fundo chato de $300 \mathrm{~mL}$, foram transferidos $10 \mathrm{~mL}$ de cada uma das soluções de Fehling nomeadas acima (Figura 2) e adicionados $40 \mathrm{~mL}$ de água. O balão foi aquecido até a ebulição em chapa aquecedora. O filtrado foi transferido para uma bureta de 25 mL e adicionado, às gotas, sobre a solução do balão em ebulição, agitando sempre, utilizando uma garra, até que esta solução mudasse de coloração azul à incolor (no fundo do balão ficou um resíduo vermelho-tijolo), por Instituto Adolfo Lutz (IAL, 2008).

Figura 2. Análise físico-química realizada, solução de Fehling

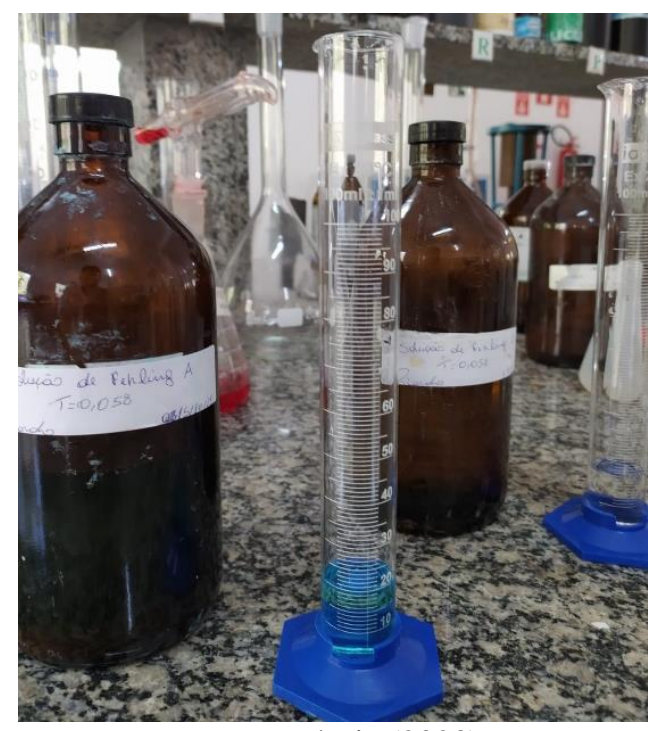

Fonte: Própria (2020).

Para determinação de acidez - aconteceu da seguinte forma: foram pesados em um Erlenmeyer de $250 \mathrm{~mL}$, aproximadamente $5 \mathrm{~g}$ da amostra, conforme, com auxílio de uma balança analítica e adicionados em cada Erlenmeyer $50 \mathrm{~mL}$ de água destilada com o auxílio de uma proveta. Os Erlenmeyer foram agitados para uma perfeita homogeneização e acrescentados 3 a 5 gotas do indicador fenolftaleína a $1 \%$. As amostras foram tituladas com uma solução de $\mathrm{NaOH}$ a $0,1 \mathrm{~N}$ previamente padronizada até a viragem da solução do incolor para a cor róseo claro, por Instituto Adolfo Lutz (IAL, 2008).

O soro de leite, microrganismos probiótico e extrato de soja foram adquiridos do Laboratório Pesquisa e Desenvolvimento de Produtos Laticínios (PDLAT/UFPB) da Universidade Federal da Paraíba Campus III, Bananeiras-PB (UFPB III). Foram elaboradas três formulações de sorvetes com $10 \%, 15 \%$ e $20 \%$ de extratos soja. 
As análises físico-químicas foram realizadas no Laboratório de Análises Físicoquímicas de Alimentos do CCHSA UFPB Campus III. Para análise físico-química foram determinados soídos solúveis totais usando um refratômetro ABBE, gordura (SOXHLET), lactose (LANE-EYNON) e acidez (titulação) segundo Instituto Adolfo Lutz (IAL, 2008).

\section{Resultados e Discussão}

Os resultados das análises físico-químicas, encontram-se na Tabela 1. Os resultados mostraram valores diferentes para os diferentes tratamentos com exceção do teor de sólidos solúveis ( ${ }^{\circ}$ Brix), que correspondem a 1,20 em todos os tratamentos.

Em sorvetes formulados com leite, teores de sólidos solúveis podem variar (SOUSA, 2013). Outro ponto importante que deve-se levar em conta é que o produto em análise não foi adicionado de nenhuma fruta, e isto pode ter influenciado também em um teor de sólidos solúveis tão baixo.

Romano (2012), analisando o teor de sólidos solúveis em iogurte simbiótico obteve um percentual de até 1,94 , o mesmo relata que não houve diferença significativa entre as demais formulações.

Tabela 1. Resultado da análise físico-química dos sorvetes

\begin{tabular}{cccc}
\hline & \multicolumn{3}{c}{ Amostras } \\
\cline { 2 - 4 } Componentes & $\mathrm{T} 1$ & $\mathrm{~T} 2$ & $\mathrm{~T} 3$ \\
\hline ' $\mathrm{Brix}$ & 1,20 & 1,20 & 1,20 \\
Gordura $(\%)$ & 40,03 & 42,72 & 52,33 \\
Lactose (\%) & 0,0055 & 0,0063 & 0,0068 \\
Acidez (\%) & 1,78 & 1,19 & 1,22 \\
\hline & T1 com $10 \%, \mathrm{~T} 2$ com $15 \%$ e T3 com $20 \%$ de extrato de soja.
\end{tabular}

Com relação aos resultados de gordura, as amostras diferiram entre si, podemos observar que a formulação 3, corresponde ao maior percentual de gordura 52, 33\%, e as demais formulações 1 e 2 os valores respectivamente são de 40,03\% e 42,72\% apresenta-se com menor quantidade de gordura. Essa diferença entre os valores em cada formulação, se dá pela quantidade de extrato adicionado. Onde por ser um extrato tem teor reduzido de gordura, além de ser uma grande fonte de proteínas, e vitaminas do complexo B (SILVA, 2008).

Foram encontrados resultados inferiores ao do presente trabalho, Bertolo (2014) ao avaliar sorvete à base de soja com adição de yacon, onde relata que o percentual de gordura encontrado foi de $12,29 \%$. 
Oliveira (2019), relatou teores de proteína divergentes em suas formulações de $2,95 \%$ e de 3,96\%, entretanto não houve diferença significativa no teor de proteínas, logo segue a linha de outros sorvetes a base de fruta.

O percentual de lactose foi um dos mais baixos encontrado, onde respectivamente foi obtido 0,0055 para tratamento $1 ; 0,0063$ para tratamento 2 e 0,0068 para o tratamento 3 ou seja a quantidade de açúcar neste sorvete é muito pequena quando comparada com outros autores.

Guedes, em sua pesquisa concluiu que, em sorvetes com baixo teor de lactose, ou com adição parcial de polpa de fruta tem boa aceitação, onde as mesmas correspondem a 35\% da intenção de compra.

Além disso com a baixa quantidade de lactose no produto, aumenta-se o interesse de consumidores por esta classe de alimentos. (MIGUEL, 2009).

A acidez variou entre $1,78 \%$ e 1,22\% o baixo valor já era esperado devido a composição do produto. A produção de ácido láctico, acetaldeído e diacetil pela fermentação láctica, modificam as características sensoriais de produtos à base de extrato de soja (FERNÁNDEZ, 2015).

Resultados superiores aos encontrados no presente trabalho foram reportados por Fernández (2015), que estudou o desenvolvimento de sorvetes probióticos à base de extrato solúvel de soja é obteve resultados de pH entre 4,37 e 4,72.

Miguel (2009), desenvolveu sorvete simbiótico à base de extrato aquoso de soja e de yacon onde constatou que na formulação de sorvete desenvolvido com 100\% de extrato de soja o pH estabelecido foi de 6.2.

\section{Conclusões}

O soro do leite pode ser uma opção barata para cultivos probióticos, e a fermentação do extrato hidrossolúvel de soja por bactérias láticas e probióticas promove as características sensoriais da bebida e confere benefícios fisiológicos ao organismo. Sendo assim, os microrganismos probióticos na formulação do sorvete simbiótico demostram que o sorvete pode ser um alimento funcional.

O sorvete simbiótico com soro do leite e extrato de soja, é uma boa alternativa para quem procura uma alimentação mais saudável. Os resultados deste trabalho podem contribuir para o desenvolvimento de novos produtos para a indústria alimentícia.

\section{Referências}

AHMAD, N.; LI, L.; YANG, X.-Q.; NING, Z.-X.; RANDHAWA, M.A. Improvements in the 
flavour of soy cheese. Food Technology and Biotechnology, v.46, n.3, p.252-261, 2008.

ANEKELLA, K.; ORSAT, V. Optimization of microencapsulation of probiotics in raspberry juice by spray drying. LWT - Food Science and Technology, v.50, n.1, p.17-24, 2013.

AGÊNCIA NACIONAL DE VIGILÂNCIA SANITÁRIA. Resolução RDC n.266, de 22 de setembro de 2005. Aprova o regulamento técnico para gelados comestíveis e preparados para geladoscomestíveis.Disponívelem:http://portal.anvisa.gov.br/wps/wcm/connect/f5d552004a9 bdc469832dc4600696f00/Resolucao_RDC_n_266_de_22_de_setembro_de_2005.pdf?MOD= AJPERES. Acesso em: 10 mai. 2020.

AGÊNCIA NACIONAL DE VIGILÂNCIA SANITÁRIA. Alimentos. Alimentos com alegações de propriedades funcionais e ou de saúde, novos alimentos/ingredientes, substâncias bioativas e probióticos. Brasília, 2008. Disponível em: http://www.anvisa.gov.br/alimentos/comissoes/tecno_lista_alega.htm. Acesso em: 16 mai. 2020.

ALVES, L.L. et al. Cream cheese as a symbiotic food carrier using Bifidobacterium animalis Bb-12 and Lactobacillus acidophilus La-5 and inulin. International Journal of Dairy Technology, v. 66, n. 1, p. 63-69, feb. 2013.

BALDISSERA, A.C.N.; DELLA BETTA, F.; PENNA, A.L.B.; LINDNER, J.D.D. Alimentos funcionais: uma nova fronteira para o desenvolvimento de bebidas proteicas à base de soro de leite. Semina: Ciências Agrárias, v.32, p.1497-1512, 2011.

BERTOLO, A.P. Sorvete a base de soja com enriquecimento nutricional pela adição de batata yacon. Orientado: Ernesto Quast 2014. 85 f. Trabalho de Conclusão de Curso (Bacharel em Engenharia de Alimentos) - Universidade Federal da Fronteira Sul, Laranjeiras do Sul.

BAŞYIĞIT, G.; KULEAŞAN, H.; KARAHAN, A.G. Viability of human-derived probiotic lactobacilli in ice cream produced with sucrose and aspartame. Journal of Industrial Microbiology \& Biotechnology, v. 33, n. 9, p. 796-800, sep., 2006.

BEDANI, R.; ROSSI, E.A.; SAAD, S.M.I. Impact of inulin and okara on Lactobacillus acidophilus La-5 and Bifidobacterium animalis Bb-12 viability in a fermented soy product and probiotic survival under in vitro simulated gastrointestinal conditions. Food Microbiology, v.34, n.2, p.382-389, 2013.

BEHRENS, J.H.; SILVA, M.A.A.P. Atitude do consumidor em relação à soja e produtos derivados. Ciência e Tecnologia de Alimentos, v.24, n.3, p.431-439, 2004.

BRUZZESE, E. et al. Impact of prebiotics on human health. Digestive and Liver Disease, v. 38, n. 2, p. 283-287, dec., 2006. 
CODRON, J.-M.; GRUNERT, K.; GIRAUD-HERAUD, E.; SOLER, L.-G.; REGMI, A. Retail sector responses to changing consumer preferences. In: REGMI, A.; GEHLHAR, M., eds. New directions in global food markets. Washington: United States. Departament of Agriculture, 2005.cap.3, p.32-46. (Agriculture Information Bulletin, n.794).

\section{COMPANHIANACIONALDEABASTECIMENTO.AcompanhamentodasafraBrasileira:g}

rãos - safra 2014/2015 - Quarto Levantamento: Janeiro/2015. Brasília: CONAB,2015.90p.Disponívelemhttp://www.conab.gov.br/OlalaCMS/uploads/arquivos/15_0 1_09_09_00_21_boletim_graos_j aneiro_2015.pdf. Acesso em: 13 mai. 2020.

FARNWORTH, E.R.; MAINVILLE, I.; DESJARDINS, M.-P.; GARDNER, N.; FLISS, I.; CHAMPAGNE, C. Growth of probiotic bacteria and bifidobacteria in a soy yogurt formulation. International Journal of Food Microbiology, v.116, n.1, p.174-181, 2007.

FOOKS, L.J.; FULLER, R.; GIBSON, G.R. Prebiotics, probiotics and human gut microbiology. International Dairy Journal, v.9, n.1, p.53-61, 1999.

FERNÁNDEZ, L.C. Desenvolvimento de sorvetes probióticos a base de extrato solúvel de soja. Orientador: Ismael Maciel de Mancilha. 2015. 89 f. Dissertação (Mestrado em Microbiologia Aplicada) - Universidade de São Paulo, Lorena.

GEISER, M. The wonders of whey protein. NSCA's Performance Training Journal, v.2, n.5, p.13-15, 2003.

GUEDES, S.M.; BEZERRA, J, J.M.V.; TEIXEIRA, A.M.; RIGO, M. Avaliação sensorial e físico-química de sorvete com baixo teor de lactose e adição de polpa de abacaxi (Ananas comosus L. Merril). Revista Unicentro, v.14, n.1, p.01-08, Guarapuava, 2018.

GIBSON, G.R. Fibre and effects on probiotics (the prebiotic concept). Clinical Nutrition Supplements, v. 1, p. 25-31, 2004.

GIBSON, G.R.; ROBERT, H.M.; VAN LOO, J.V.; RASTALL, R.A.; ROBERFROID, M.B. Dietary modulation of the human colonic microbiota: updating the concept of prebiotics. Nutrition Research Reviews, v.17, n.2, p.259-275, 2004.

HAMILTON-MILLER, J.M.T. Probiotics and prebiotics in the elderly. Postgraduate Medical Journal, v.80, n.946, p.447-451, 2004.

HASLER, C.M.; BROWN, A.C.; AMERICAN DIETETIC ASSOCIATION. Position of the American Dietetic Association: functional foods. Journal of the American Dietetic Association, v.109, n.4, p.735-746, 2009. 
HAULY, M.C. de O.; MOSCATTO, J.A. Inulina e oligofrutoses: uma revisão sobre propriedades funcionais, efeito prebiótico e importância na indústria de alimentos. Semina: Ciências Exatas e Tecnológicas, Londrina, v. 23, n. 1, p. 105-118, dez., 2002.

HEENAN, C.N.; ADAMS, M.C.; HOSKEN, R.W.; FLEET, G.H. Survival and sensory acceptability of probiotic microorganisms in a nonfermented frozen vegetarian dessert. LWT - Food Science and Technology, v.37, n.4, p.461-466, 2004.

HOMAYOUNI, A. et al. Effect of microencapsulation and resistant starch on the probiotic survival and sensory properties of synbiotic ice cream. Food Chemistry, v. 111, n. 1, p. 50-55, nov., 2008.

HOMAYOUNI, A. et al. Growth and survival of some probiotic strains in simulated ice cream conditions. Journal of Applied Sciences, v. 8, n. 2, p. 379-382, 2008.

HOMAYOUNI, A. et al. Factors influencing probiotic survival in ice cream: a review. International Journal of Dairy Science, v. 7, n. 1, p. 1-10, jan./mar., 2012.

INSTITUTO ADOLFO LUTZ. Métodos físico-químicos para análise de alimentos. $4^{\mathrm{a}}$ ed., $1^{a}$ ed. Digital, São Paulo, 2008. 1020p.

INSTITUTO ADOLFO LUTZ. Normas Analíticas do Instituto Adolfo Lutz. v. 1: Métodos químicos e físicos para análise de alimentos, 3. ed. São Paulo: IMESP, 1985, p. 206.

INSTITUTO ADOLFO LUTZ. Métodos físico-químicos para análise de alimentos. $4^{\mathrm{a}}$ ed., $1^{a}$ ed. Digital, São Paulo, 2008. 1020p.

INSTITUTO ADOLFO LUTZ. Métodos físico-químicos para análise de alimentos. $4^{\mathrm{a}}$ ed., $1^{\mathrm{a}}$ ed. Digital, São Paulo, 2008. 1020p.

KENT, R.M.; DOHERTY, S.B. Probiotic bacteria in infant formula and follow-up formula: microencapsulation using milk and pea proteins to improve microbiological quality. Food Research International, v.64, p.567-576, 2014. [Review].

KOMATSU, T.R.; BURITI, F.C.A.; SAAD, S.M.I. Inovação, persistência e criatividade superando barreiras no desenvolvimento de alimentos probióticos. Revista Brasileira de Ciências Farmacêuticas, v. 44, n. 3, p. 329-347, jul./set., 2008.

KUMAR, V.; RANI, A.; SOLANKI, S.; HUSSAIN, S.M. Influence of growing environment on the biochemical composition and physical characteristics of soybean seed. Journal of Food Composition and Analysis, v.19, n.2/3, p.188-195, 2006. 
LIONG, M.-T.; EASA, A.M.; LIM, P.-T.; KANG, J.-Y. Survival, growth characteristic and bioactive potential of Lactobacillus acidophilus in soy-based cream cheese. Journal of the Science of Food and Agriculture, v.89, n.8, p.1382-1391, 2009.

LIU, D.-M.; LI, L.; YANG, X.-Q.; LIANG, S.-Z.; WANG, J.-S.Survivability of Lactobacillus rhamnosus during the preparation of soy cheese. Food Technology and Biotechnology, v.44, n.3, p.417-422, 2006.

MARSHALL, R.T. Frozen Desserts In: MARTH, E. H.; STEELE, J. L. Applied Dairy Microbiology. 2rd. New York: Marcel Dekker, 2001. cap. 4. p. 93-125.

MIGUEL, D.P. Desenvolvimento de sorvete de "iogurte" simbiótico à base de extrato aquoso de soja e de yacon (Smallanthus sonchifolius) fermentado com Lactobacillus acidophilus CRL 1014. 118f. 2009. Tese (Doutorado em Alimentos e Nutrição) - Universidade Estadual "Júlio de Mesquita Filho", Araraquara.

MARTINEZ, R.C.; BEDANI, R. SAAD, S.M. Scientific evidence for health effects attributed to the consumption of probiotics and prebiotics: an update for current perspectives and future challenges. British Journal of Nutrition, v.15, 2015.

MATTILA-SANDHOLM, T. et al. Technological challenges for future probiotic foods. International Dairy Journal, v. 12, n. 2, p. 173-182, feb./mar., 2002.

MONTAGNER, G.E.; STORCK, C.R. Sorvete com extrato hidrossolúvel de arroz: análise físico-química e sensorial. Ciência e Tecnologia de Alimentos, v.15, Santa Maria, 2020.

NOUSIA, F.G.; ANDROULAKIS, P.I.; FLETOURIS, D.J. Survival of Lactobacillus acidophilus LMGP-21381 in probiotic ice cream and its influence on sensory acceptability. International Journal of Dairy Technology, v. 63, n. 1, p. 1-7, feb., 2011.

OLIVEIRA, B.C. Desenvolvimento e caracterização de sorvete enriquecido com licopeno. Orientadora: Maria Josiane Sereia. 2019. 56 f. Trabalho de Conclusão de Curso (Engenheiro de Alimentos) - Universidade Tecnológica Federal do Paraná, Campo Mourão.

PANDIYAN, C. et al. Effect of incorporation of inulin on the survivability of Lactobacillus acidophilus in synbiotic ice cream. International Food Research Journal, v. 19, n. 4, p. 1729$1732,2012$.

PINTOR, A.; SEVERIANO-PÉREZ, P.; TOTOSAUS, A. Optimization of fat-reduced ice cream formulation employing inulin as fat replacer via response surface methodology. Food Science and Technology International, v. 00, n. 0, p. 1-12, 2013.

ROBERFROID, M. B. Prebiotics and probiotics: are they functional foods?. The American Journal of Clinical Nutrition, v. 71, n. 1, p. 1682-1687, 2000. 
ROMANO, C. C. Influência da inulina nas características químicas, sensoriais e sobrevivência do L. acidofilus em frozen yogurt simbiótico com teor reduzido de lactose. 2012. 32 f. Trabalho de Conclusão de Curso (Tecnologia de Alimentos) - Universidade Tecnológica do Paraná, Campo Mourão.

ROBERFROID, M.B. General introduction: prebiotics in nutrition. In: GIBSON, G.R.; ROBERFROID, M.B., ed. Handbook of prebiotics. Boca Raton: CRC, 2008a. p.1- 11.

ROSSI, E.A.; CAVALLINI, D.C.U.; MANZONI, M.S.J.; ROSSI, P.R. Produtos probióticos e prebióticos à base de soja. In: SAAD, S.M.I.; CRUZ, A.G.; FARIA, J.A.F., eds. Probióticos e prebióticos em alimentos: fundamentos e aplicações tecnológicas. São Paulo: Varela, 2011. cap.22, p.541-563.

SAAD, S.M.I. Probióticos e prebióticos: o estado da arte. Revista Brasileira de Ciências Farmacêuticas, v. 42, n. 1, p. 1-16, jan./mar., 2006.

SÁNCHEZ, B.; REYES-GAVILÁN, C.G.; MARGOLLES, A.; GUEIMONDE, M. Probiotic fermented milks: present and future. International Journal of Dairy Technology, v.62, n.4, p.472-483, 2009.

SOUZA, J. C. B. et al. Sorvete: composição, processamento e viabilidade da adição de probiótico. Brazilian Journal of Food and Nutrition, v. 21, n. 1, p. 155-165, jan./mar., 2010.

SOUSA, G. L. Desenvolvimento de sorvete simbiótico de graviola (Annona muricara L.) com teor reduzido de gordura e avaliação da resistência gastrointestinal dos probióticos in vitro. 2013. $154 \mathrm{f}$. Tese (Doutorado em Tecnologia de Alimentos) - Universidade de São Paulo, São Paulo.

GOFF, H.D.; HARTEL, R.W. Ice Cream. New York: Springer US, 2013. 462p.

SOUZA, J. C. B. et al. Sorvete: composição, processamento e viabilidade da adição de probiótico. Brazilian Journal of Food and Nutrition, v. 21, n. 1, p. 155-165, jan./mar., 2010.

SILVA, D.T. Extrato de soja: características, métodos de obtenção e compostos benéficos a saúde humana. Orientador: Valdecir Carlos Ferri. 2008. 34 f. Trabalho de Conclusão de Curso (Bacharelado em Química) - Universidade Federal de Pelotas, Pelotas, 2008.

SU, P.; HENRIKSSON, A.; MITCHELL, H. Prebiotics enhance survival and prolong the retention period of specific probiotic inocula in an in vivo murine model. Journal of Applied Microbiology, v.103, n.6, p.2392-2400, 2007.

TAVARES, T.; MALCATA, F.X. Whey and Whey Powders: Protein Concentrates and Fractions. In: CABALLERO, B.; FINGLAS, P.M.; TOLDRÁ, F., eds. Encyclopedia of Food and Health. Oxford: Academic Press, 2016. 
TRIPATHI, M.K.; GIRI, S.K. Probiotic functional foods: survival of probiotics during processing and storage. Journal of Functional Foods, v.9, p.225-241, 2014.

USDEC. Reference manual for US whey and lactose products. Arlington, VA: US Dairy ExportCouncil.2006.

Disponívelem:http://usdec.files.cmsplus.com/PDFs/2008ReferenceManuals/Whey_Lactose_R eference_Manual_Complete2_Opti mized.pdf. Acesso em: 03 jun. 2020.

VARGAS, L. A.; OLSON, D. W.; ARYANA, K. J. Whey protein isolate improves acid and bile tolerances of Streptococcus thermophilus ST-M5 and Lactobacillus delbrueckii ssp. bulgaricus LB-12. Journal of Dairy Science, v.98, n.4, p.2215-2221, 2015.

VIEIRA, A.F.; ROCHA, A.P.T.; SANTOS, D.C.; MORAIS, H.M.B.R.; ALMEIDA, R.D.; SILVA, S.N. Aceitabilidade e caracterização física e físico-química de doce tipo doce de leite produzido com extrato hidrossolúvel de soja. Revista Principia, n.42, João Pessoa, 2018.

WEI, Q.-K.; CHEN, T.-R.; CHEN, J.-T. Using of Lactobacillus and Bifidobacterium to product the isoflavone aglycones in fermented soymilk. International Journal of Food Microbiology, v.117, n.1, p.120-124, 2007. 